\title{
Pangênese, genes, epigênese
}

\section{Pangenesis, genes, epigenesis}

\author{
Fernanda Gonçalves Arcanjo \\ Mestranda, Programa de Pós-graduação em \\ História das Ciências e das Técnicas e Epistemologia/Universidade \\ Federal do Rio de Janeiro; pesquisadora, Laboratório de Genética \\ Marinha e Evolução/Departamento de Biologia Marinha/ \\ Universidade Federal Fluminense (UFF). \\ Outeiro São João Batista, s.n. \\ 24001-970 - Niterói - RJ - Brasil \\ fgarcanjo@gmail.com
}

\section{Edson Pereira Silva}

Professor, Laboratório de Genética Marinha e Evolução/Departamento de Biologia Marinha/UFF.

Outeiro São João Batista, s.n.

24001-970 - Niterói - RJ - Brasil

gbmedson@vm.uff.br

Recebido para publicação em agosto de 2015

Aprovado para publicação em maio de 2016.
ARCANJO, Fernanda Gonçalves; SILVA, Edson Pereira. Pangênese, genes, epigênese. História, Ciências, Saúde Manguinhos, Rio de Janeiro, v.24, n.3, jul.-set. 2017, p.707-726.

\section{Resumo}

Em 1868, Darwin publica seu livro The variation of animals and plants under domestication, no qual expõe sua teoria da hereditariedade. Nela se encontrava o pressuposto de que o desenvolvimento era fundamental para compreensão do processo evolutivo. No presente trabalho, é feita uma releitura da teoria darwiniana da pangênese, no intuito de rediscutir seu valor histórico. Conclui-se que a teoria da pangênese estava bem adequada a seu tempo e, mais do que isso, é possível encontrar ressonâncias de seu pressuposto em trabalhos das novas áreas biologia evolutiva do desenvolvimento (evo-devo) e epigenética.

Palavras-chave: Charles Darwin (18091882); pangênese; epigenética; evo-devo; epistemologia.

\section{Abstract}

In 1868, Darwin published his book The variation of animals and plants under domestication, which laid out his theory of heredity. This included the assumption that development was essential to understanding the evolutionary process. This present article reassesses the Darwinian theory of pangenesis in order to revisit its historical value. The conclusion is that the theory of pangenesis was well-suited to its time, and additionally, reflections of this assumption can be found in work in new areas known as evolutionary biology of development (evodevo) and epigenetics.

Keywords: Charles Darwin (1809-

1882); pangenesis; epigenetics; evo-devo; epistemology. 


\section{Uma hipótese provisória}

Em 1859, foi publicado pela primeira vez o livro icônico de Charles Robert Darwin (18091882), On the origin of species by means of natural selection or the preservation of favoured races in the struggle for life, no qual o naturalista inglês apresentou sua teoria evolutiva. Cinco outras edições foram publicadas, sendo a sexta e última datada de 1872. Sua teoria definindo evolução como "descendência com modificação guiada por seleção natural" provocou uma avalanche de críticas positivas e negativas nos primeiros anos que seguiram sua publicação. As posições a respeito da teoria darwiniana amadureceram. Surgiram cada vez mais adeptos, mas também mais críticos, tais como George Mivart (1827-1900), Samuel Butler (1835-1902), William Thomson (1827-1907) e Fleming Jenking (1833-1885). As críticas negativas tinham natureza diversa, mas grande parte dizia respeito às lacunas no sistema explicativo da teoria, das quais Darwin esteve ciente, mas não pôde preencher de início. Por exemplo, a falta dos elos perdidos que demonstrariam a "descendência com modificação", ou a falta de dados empíricos para se verificar a atuação da seleção natural, ou, ainda, a falta de uma explicação para a origem e natureza da variação e de um mecanismo de herança bem definido.

Entre essas lacunas, o problema da origem e natureza da variação herdável era crucial. Isso porque as grandes novidades da teoria darwiniana eram (1) a identificação da variação presente nas populações naturais a partir de uma perspectiva materialista, assim a variação individual deixou de ser vista como uma imperfeição em relação a um tipo ideal e passou a ser entendida como a realidade do mundo natural, e (2) a concepção de formação de novas espécies como um processo de transformação dessa variação individual (intrapopulacional) em variação entre grupos (interpopulacional). Era, portanto, pressuposto da teoria que houvesse um estoque virtualmente infinito de variação herdável nas populações naturais para que o processo evolutivo descrito pudesse gerar tão grande variedade de espécies. Nas palavras de Darwin (1868, p.192), "o poder da seleção... depende absolutamente da variação entre seres vivos. Sem variação nada pode ser produzido". ${ }^{1}$

Embora Darwin não tenha discutido apropriadamente em On the origin quais deveriam ser a origem e a natureza da variação e como ela seria herdada ao longo das gerações, ele abordou brevemente no livro algumas noções acerca do assunto que eram amplamente aceitas e muito populares nos séculos XVIII e XIX, como o "uso e desuso" e a "herança de caracteres adquiridos". No entanto, essas noções apenas faziam parte das elaboradas ideias de Darwin, que viriam à tona mais tarde, a respeito do tema.

É apenas em 1868 que Darwin vem a publicar, pela primeira vez, sua teoria da hereditariedade, no último capítulo de seu livro The variation of animals and plants under domestication. Essa obra foi uma extensão do primeiro capítulo de On the origin, que, assim como ele, tratava de temas importantes a respeito da evolução na perspectiva da domesticação e da seleção artificial, esta última muito explorada por Darwin na proposição da seleção natural como uma importante força atuando sobre a transmutação das espécies. No capítulo 27 de The variation, nomeado "The provisional hypothesis of pangenesis" ("A hipótese provisória da pangênese"), Darwin transcreve a teoria na qual seus estudos a respeito de variação, herança, desenvolvimento e reprodução culminaram (Olby, 1963). 
Embora Darwin tenha identificado a pangênese como uma hipótese, é seguro se referir a ela como uma teoria. ${ }^{2}$ Isso porque, apesar do seu caráter especulativo, ela fornecia um sistema explicativo completo para o fenômeno da herança, rico em evidências empíricas e capaz de explicar a maioria dos problemas entendidos na época como questões de herança, mas que até então continuavam sem respostas.

\section{Pangênese e herança}

A teoria da pangênese (do grego pan, todo, e genesis, origem/nascimento) se baseia na proposta de que toda a organização do corpo é capaz de reproduzir a si mesma por meio de suas partes. Na seguinte passagem de The variation, Darwin (1868, p.374) resume os principais pressupostos de sua teoria:

Eu presumo que as células, antes de sua completa conversão em material completamente passivo ou 'material formado', liberam pequenos grânulos ou átomos, que circulam livremente através do sistema e, quando nutridos apropriadamente, multiplicam-se por autodivisão, transformando-se subsequentemente em células como aquelas das quais derivam. Esses grânulos, por questão de distinção, podem ser chamados gêmulas celulares, ou, como a teoria celular ainda não se encontra completamente estabelecida, apenas gêmulas. Elas supostamente são transmitidas dos parentais para a progênie, e, geralmente, se desenvolvem na geração seguinte, mas, frequentemente, são transmitidas em estado dormente por várias gerações até que então se desenvolvem. O desenvolvimento das gêmulas é, supostamente, dependente da união destas com outras células ou gêmulas parcialmente desenvolvidas que lhe precedem no curso regular de crescimento... Gêmulas, supostamente, são liberadas por toda célula ou unidade [do corpo], não apenas no estado adulto, mas durante todas as etapas do desenvolvimento. Por fim, eu presumo que as gêmulas em seu estado dormente apresentam uma afinidade mútua entre si, levando a sua agregação nas sementes ou órgãos sexuais. Portanto, estritamente falando, não é o sistema reprodutivo, nem as sementes, que são responsáveis pela geração de novos organismos, mas sim as células do corpo propriamente ditas. Essas premissas constituem a hipótese provisória que eu nomeei Pangênese. ${ }^{3}$

É ao desenvolvimento mediado pelas gêmulas que Darwin atribui o poder de explicar como se dava a herança. A transferência de gêmulas dos parentais para os descendentes explicava a semelhança entre estes. A transferência de gêmulas em estado de dormência era capaz de explicar o atavismo, ou reversão, que dizia respeito ao reaparecimento de uma característica ancestral em um dado indivíduo após ausente na população por curto ou longo período de tempo, às vezes por milhares de gerações. A reversão foi um dos tópicos mais desenvolvidos por Darwin ao longo do capítulo de The variation dedicado à pangênese, no qual se refere a ela como "o mais admirável de todos os atributos da herança" (Darwin, 1868, p.372). ${ }^{4}$ De acordo com Geison (1969, p.410), a possibilidade de um modelo para explicar o problema da reversão foi um dos pontos fundamentais para que Darwin pudesse elaborar sua teoria da hereditariedade.

Além disso, a pangênese ainda explicava que, uma vez que as gêmulas devessem se desenvolver numa determinada ordem, traçando, assim, o desenvolvimento do organismo, diversas aberrações poderiam ser entendidas como erros na conformação dos agregados 
de gêmulas, que teriam levado ao desenvolvimento de gêmulas em local ou momento inadequados.

Já o pressuposto de que as gêmulas seriam produzidas ao longo de toda a vida do indivíduo corroborava a lei da herança de caracteres adquiridos. Dessa forma, todas as mudanças que o organismo sofresse ao longo da vida seriam codificadas em gêmulas, numa quantidade proporcional à idade em que a mudança se desse (que seria proporcional, também, à influência dessa mudança sobre as gerações seguintes, processo sobre o qual haveria, ainda, a ação de seleção natural). Assim como a reversão, a herança do adquirido foi, indiscutivelmente, um dos grandes focos da teoria da pangênese, na qual foi incorporada como mais do que uma simples repetição elaborada da herança "lamarckista".

O objetivo explícito de Darwin com a teoria da pangênese, portanto, era fornecer uma explicação unificada e universal para aqueles fenômenos, até então não esclarecidos, mas que ele acreditava estarem envolvidos com a herança. No entanto, esse, certamente, não era seu único objetivo. A pangênese havia sido proposta não apenas para explicar a variação herdável, mas também um grande conjunto de fenômenos do desenvolvimento, como será discutido melhor adiante.

\section{Pangênese e variação}

Desde 1838, Darwin teorizava sobre as possíveis causas da variação herdável nos seres vivos (Winther, 2000). Com a publicação, em 1875, da segunda e última edição de The variation, ele concluiu seus estudos acerca do assunto incorporando-os à pangênese, de modo a fornecer uma explicação única para todos os mecanismos que, de acordo com Darwin, eram responsáveis pelo surgimento da variação entre indivíduos. Neste fragmento, retirado da segunda edição de The variation, ele resume suas "leis da variação":

Finalmente, nós vemos na hipótese da pangênese que a variação depende de, pelo menos, dois grupos de causas distintos. Primeiramente, a deficiência, superabundância e transposição de gêmulas, e o redesenvolvimento daquelas que há muito se encontravam dormentes: as gêmulas, elas próprias, não tendo sofrido nenhuma modificação; e tais mudanças serão responsáveis por grande parte da variação flutuante. Em segundo lugar, a ação direta de mudanças nas condições sobre a organização, e o uso e desuso de partes; e, nesse caso, as gêmulas das unidades modificadas serão, elas mesmas, modificadas e depois de suficientemente multiplicadas, vão suplantar as gêmulas antigas e se desenvolver em novas estruturas (Darwin, 1875, p.390). ${ }^{5}$

Os dois grupos de causas a que Darwin se referiu nesse parágrafo são os que ele denominou, em outros momentos, de mecanismos de efeitos indireto e direto. No que dizia respeito aos eventos que geravam variação, Darwin entendia que a causa primária era, na maioria dos casos, uma mudança nas condições de vida, ou seja, no ambiente. Nos mecanismos de efeito indireto o ambiente afetaria apenas os órgãos reprodutivos do indivíduo - regiões que ele considerava mais suscetíveis -, produzindo variação a partir de alterações na organização dos agregados de gêmulas, sem que houvesse qualquer mudança nas gêmulas propriamente ditas. A mudança, portanto, seria expressa apenas nas gerações seguintes. É importante ressaltar que, embora no trecho destacado de The variation Darwin tenha assumido a reversão como uma fonte de variação, em outros momentos do livro ele enfatiza que os caracteres retomados 
por reversão não poderiam ser qualificados como variação nova (Darwin, 1868, p.304; 1875, p.239). Dessa forma, as novas variações resultantes de mecanismos de efeito indireto seriam aleatórias, ou seja, poderiam ser vantajosas ou desvantajosas para o indivíduo na dependência das condições do meio e dos outros indivíduos da população. Sendo assim, seria sobre esse grupo de variação que a seleção natural poderia agir.

Já nos mecanismos de efeito direto, alterações nas condições do meio provocariam mudanças no próprio corpo do indivíduo afetado, e essas mudanças seriam passadas ao longo das gerações pela herança de gêmulas também modificadas. Entre os mecanismos de efeito direto estavam a "ação direta do meio sobre o organismo", a "aclimatização por meio da mudança de hábitos" e o "uso e desuso" (Winther, 2000). Darwin acreditava que o "uso e desuso" era o mecanismo fonte de maior quantidade de variação por efeito direto. Portanto, as variações originadas por mecanismo de efeito direto eram, geralmente, variações necessariamente adaptativas.

"Uso e desuso" foi um dos temas aos quais Darwin mais se dedicou no capítulo 24, "Laws of variation" ("Leis da variação"), de The variation, principalmente na sua segunda edição. No entanto, o autor tinha consciência de que a maior parte das variações não poderia ser adaptativa, pois, desse modo, não haveria material para que a seleção natural pudesse agir. Em correspondência a Asa Gray, datada de 8 de maio de 1868, Darwin (8 maio 1868) explicita o problema de que "se as variações corretas ocorressem, e nenhuma outra, a seleção natural seria supérflua". ${ }^{6}$ Até suas últimas publicações, Darwin (1859, p.6; e edições subsequentes) insistiu que a maior parte da variação herdável surgia por mecanismo de efeito indireto e a "seleção natural era o mais importante, embora não único, meio de modificação [das espécies]". ${ }^{7}$

\section{Pangênese e teoria evolutiva}

A publicação do livro The variation of animals and plants under domestication, em 1868, nove anos após a primeira publicação de On the origin, no florescer das críticas à sua teoria evolutiva, levou alguns autores a propor que Darwin teria escrito a pangênese no intuito de utilizá-la como uma hipótese ad hoc para sua teoria evolutiva (Geison, 1969, p.379). No entanto, as críticas que mais repercutiram na época, como a de Fleeming Jenking (1867), foram manifestadas pouco antes da publicação de The variation, inclusive após o livro ser entregue para impressão (Vorzimmer, 1963, p.386). Além disso, em correspondência ao geólogo Charles Lyell (1797-1875), datada de 1867, Darwin explicita que já trabalhava nessa teoria havia mais de 25 anos (Darwin, 22 ago. 1867). Desse modo, ele não teria produzido sua teoria de herança apenas para tentar salvar sua teoria evolutiva (Olby, 1963; Ghiselin, 1975). Seus objetivos com a teoria da pangênese, na verdade, vinham de muito antes das críticas a On the origin.

Não faria sentido, no entanto, enxergar a teoria da pangênese como independente ou desconectada da teoria evolutiva darwiniana. Ambas estão intimamente relacionadas em diversos sentidos, como identificado, por exemplo, na discussão muito enfatizada na pangênese de que as espécies de reprodução sexuada, de reprodução assexuada, de reprodução por partenogênese ou com alternância reprodutiva, apresentam todas a mesma base de desenvolvimento. Embora não seja explicitada, essa relação intrínseca entre os diferentes tipos de reprodução observados em populações naturais seria uma evidência para o argumento da 
evolução como "descendência com modificação". Olby (1966, p.99, 100) defende, inclusive, que esse tema teria sido o ponto de partida da teoria da pangênese.

Embora Darwin não tenha escrito sua teoria de herança numa tentativa de salvar sua teoria evolutiva, é indiscutível que, para ele, dar uma resposta para a origem e natureza da variação era um dos seus principais objetivos com a sua "hipótese provisória da pangênese", senão o objetivo principal. Afinal, sabia que suas conclusões a respeito do processo de transmutação das espécies permaneceriam incompletas até que ele apresentasse fundamentos para herança e variação (Liu, Li, 2012).

Em maio de 1865, Darwin enviou, pela primeira vez, um manuscrito recém-acabado da pangênese para seu colega e crítico Thomas Huxley (1825-1895). Fica claro pelo conteúdo de uma das cartas trocadas entre eles que o estímulo de Huxley (16 jul. 1865; Darwin, 17 jul. 1865) a favor da publicação da pangênese foi crucial para a decisão que Darwin tomou de incorporá-la à versão final de The variation. Isso, associado à intensa demanda da comunidade científica por uma resposta para a origem e natureza da variação e sua herança, formou, provavelmente, o conjunto de motivações que encorajou Darwin a publicar sua "hipótese provisória".

\section{Uma teoria do desenvolvimento}

Assim como muitos de seus contemporâneos, Darwin acreditava que a evolução biológica deveria estar intimamente relacionada ao processo de desenvolvimento dos seres vivos. No século XIX, o estudo do desenvolvimento era quase sinônimo de embriologia, e boa parte dos trabalhos na área apresentava algum viés evolutivo. Estava bem estabelecida a visão de que a evolução era movida, basicamente, por alterações no desenvolvimento (Gilbert, Optiz, Raff, 1996).

Em 1866, Ernst Haeckel (1834-1919) postulou o que seria chamado posteriormente de teoria da recapitulação com a noção de que a "ontogenia recapitula a filogenia". De acordo com esta, o estudo de morfologia e embriologia comparativas das espécies seria capaz de evidenciar o caminho do processo evolutivo a partir das semelhanças entre grupos. A teoria ganhou muitos adeptos, e, em pouco tempo, paleontólogos também se inseriram nessa linha com o estudo do registro fóssil. Alguns associavam os resultados desses estudos a um processo evolutivo linear de progresso, na tradição lamarckista; outros, defensores da teoria evolutiva darwiniana, associavam esses resultados a ramos de uma árvore da vida e perseguiam a identificação de ancestrais comuns (Bowler, 2002).

No entanto, não havia propostas sólidas para um mecanismo fisiológico que sustentasse essas noções. Os numerosos estudos em evolução acoplados ao desenvolvimento prosseguiam, portanto, de maneira pouco sistemática, incapazes de fornecer explicações gerais para o processo evolutivo. Darwin, por sua vez, compreendia que, uma vez desvendados os mecanismos do desenvolvimento, muito seria esclarecido a respeito da evolução, principalmente no que dizia respeito às causas da variação, responsáveis por mover esse processo.

Assim, a pangênese foi, também, a inauguração da busca de um mecanismo do desenvolvimento capaz de fornecer uma orientação geral para estudos específicos sobre a evolução dos táxons. Mais do que uma teoria de herança, a pangênese era uma teoria do 
desenvolvimento. Como aponta Ghiselin (1975, p.47), "ela foi uma tentativa de lidar com esse aspecto de desenvolvimento da biologia, com suas implicações evolutivas, essa era a racionalização básica da pangênese". ${ }^{8}$

Portanto, é possível identificar um último, e particularmente ambicioso, objetivo de Darwin com a publicação de sua teoria da pangênese. Ela parece ser também um projeto darwiniano de sintetizar o estudo do desenvolvimento com o estudo da evolução (Ghiselin, 1975, p.51). Era, no entanto, apenas uma "hipótese provisória". Darwin não esperava que a pangênese respondesse a todos os problemas do desenvolvimento e se encaixasse perfeitamente com os estudos em evolução, mas, provavelmente, acreditava que ela era um primeiro passo para o enquadramento das duas disciplinas numa só área de estudo.

\section{Pangênese e genes}

Apesar de se configurar em uma iniciativa notável, a pangênese darwiniana jamais teve chance, em seu tempo, de ser apreciada sob essa perspectiva. Em algumas décadas, os trabalhos em evolução/desenvolvimento cairiam num abismo conjectural devido ao novo paradigma ${ }^{9}$ que viria a ser estabelecido na área. Esse se iniciava na virada do século XIX para o século XX, com a "redescoberta" do trabalho de Gregor Mendel (1822-1884) com ervilhas-de-cheiro (1865) de modo independente pelos pesquisadores Carl Erich Correns (1864-1933), Erich Tschermak (1871-1962) e Hugo de Vries (1848-1935). ${ }^{10}$

Ao propor a herança particulada a partir de pares de fatores hereditários com segregação independente, Mendel produziu um mecanismo absolutamente heurístico para explicar a herança e que tinha como base a linguagem matemática. Com a redescoberta do trabalho de Mendel, era inaugurada, então, a disciplina da genética, que teve como um de seus principais continuadores o "grupo das drosófilas", comandado por Thomas Hunt Morgan (1866-1945).

A ascensão da genética, no entanto, teve como consequência uma rediscussão dos trabalhos de Darwin. A evolução darwiniana entrava em aparente contradição com a herança mendeliana; afinal, uma teoria se dedicava a explicar o fenômeno da mudança, e a outra, o fenômeno da estabilidade (Silva, 2001). O modelo mendeliano lidava com a variação discreta, descontínua, e a transmissão de características de parentais para descendentes se dava de forma inalterada em combinações matematicamente previsíveis de fatores hereditários (Bizzo, 2008). Já a teoria evolutiva darwiniana enfatizava a importância para a evolução da variação contínua presente nas populações naturais, mantendo que a evolução era um processo lento e gradual de acúmulo de pequenas variações a partir de seleção natural. Por esse motivo, a teoria de Mendel parecia para muitos naquele momento mais alinhada com a teoria evolutiva mutacionista de De Vries, que previa que a evolução se dava em saltos, gerando novas espécies abruptamente por meio de eventos da mutação (Sturtevant, 1967; Silva, 2001; Silva, Andrade, 2012).

Apesar da bem estabelecida contradição entre a evolução darwiniana e a herança mendeliana, havia aqueles, como Hermann Joseph Muller (1890-1967), aluno de Morgan, que acreditavam que tais teorias poderiam ser, de alguma forma, complementares e buscavam conectá-las (Silva, 2001). Foi, no entanto, apenas na década de 1930 que a contradição entre o darwinismo e o mendelismo pôde ser superada, o que se deu por meio dos trabalhos de Ronald Fisher (1890-1962), com seu livro The genetical theory of natural selection (1930), John 
Haldane (1892-1964), com o livro The causes of evolution (1932) e Sewall Wright (1889-1988), com seu artigo "Evolution in mendelian populations", publicado na revista Genetics (1931). ${ }^{11}$ Nascia, assim, a teoria sintética da evolução (TSE), alinhando a perspectiva materialista da evolução darwiniana ao modelo matemático de herança mendeliano (Silva, 2001; Silva, Andrade, 2012).

Portanto, embora a teoria evolutiva de Darwin houvesse prevalecido, não havia mais lugar para a sua "hipótese provisória da pangênese". Os pares de fatores mendelianos, agora genes, explicavam a herança de maneira muito mais coerente que as gêmulas de Darwin. Mesmo que não houvesse evidência física para nenhum dos dois, experimentos matematicamente robustos corroboravam a existência de genes segregando independentemente ao longo das gerações. As gêmulas, por sua vez, foram esquecidas envoltas no campo das especulações abstratas.

Somado a isso, os embriologistas desacreditavam cada vez mais que os trabalhos em evolução pudessem gerar frutos concretos (a teoria da recapitulação perdera relevância na comunidade científica, ganhando um viés pseudocientífico) e passaram a perseguir uma abordagem mais experimental do estudo de embriologia, sem grande correlação com evolução, de modo que a disciplina recuperasse credibilidade (Gilbert, Optiz, Raff, 1996). O estudo do desenvolvimento havia rompido com a evolução, e, nesse contexto, foi excluído da síntese evolutiva. O poder heurístico do modelo mendeliano de herança redefinia a evolução apenas como "mudança nas frequências gênicas" (Dobzhansky, 1937), e a macroevolução passava a ser compreendida como o acúmulo do processo microevolutivo. ${ }^{12}$

\section{Pangênese e evo-devo}

No início do século XX, a genética tornou-se "a menina dos olhos" da teoria evolutiva. Havia, no entanto, um pequeno grupo inserido no núcleo de pesquisa que se desenvolvia em torno da teoria sintética que insistia na importância do acoplamento do desenvolvimento à revolucionária genética para o estudo da evolução. Entre eles estavam Ernst Hadorn (19021976) e Conrad Waddington (1905-1975), que exerceram papel coadjuvante nessa tendência. Hadorn trabalhou por muitos anos no efeito de mutações sobre o desenvolvimento de moscas do gênero Drosophila. Waddington também produziu diversos trabalhos em genética e desenvolvimento com o modelo de Drosophila e acreditava que essas duas áreas se uniriam, eventualmente, levando à formação de uma nova disciplina (Holliday, 2006). Em boa parte de sua carreira, Waddington se empenhou em trabalhos teóricos, e, hoje, ele é mais conhecido por suas noções de canalização - que se refere ao fato de que o desenvolvimento, geralmente, leva aos mesmos resultados independentemente de variações nos genes ou nas condições ambientais, consequência da seleção natural agindo de modo conservador - e plasticidade fenotípica - que diz respeito ao fato de que células geneticamente idênticas podem desenvolver estrutura e função completamente diferentes. Também é frequentemente lembrado por ter cunhado o termo "epigenética" para designar os eventos responsáveis pelo desdobramento do programa genético do desenvolvimento.

Apesar dos trabalhos desses e outros pesquisadores interessados na relação entre ontogenia e filogenia, apenas no final do século XX que o desenvolvimento voltou a interessar os evolucionistas. De acordo com Carroll (2008), a biologia evolutiva do desenvolvimento como disciplina (conhecida hoje como evo-devo) iníciou com a evidenciação, durante a 
década de 1980, dos genes homeobox (McGinnis et al., 1984; Scott, Weiner, 1984). Esses genes apresentam sequências muito conservadas que codificam proteínas importantes na regulação da expressão gênica. Alguns deles estão presentes tanto em animais quanto em vegetais e fungos. Hoje já se conhecem diversos tipos de genes homeobox, no entanto, os mais estudados pela evo-devo são os genes hox. Estes são conservados em diferentes classes de animais e exercem papel crucial na formação de diversas partes do corpo durante as primeiras fases do desenvolvimento (Graham, Papalopulu, Krumlauf, 1989; Duboule, Dollé, 1989). Dessa forma, restam poucas dúvidas sobre a importância desses genes na evolução da anatomia do grupo animal (Arthur, 2002; Pick, Heffer, 2012).

Outros autores defendem que a inauguração da evo-devo estaria relacionada com o livro Ontogeny and phylogeny de Stephen Jay Gould (1977), reinstituindo, a partir das novas técnicas da biologia molecular, a importância da heterocronia - mudança do momento do desenvolvimento de uma estrutura - como um mecanismo de produção de mudança para o processo evolutivo (ideia originalmente proposta por Haeckel no século XIX). Para Hall (2003), a verdadeira origem da evo-devo remete ao século XIX, com a publicação de On the origin of species, de Darwin. On the origin teria sido um marco para o início da tradição do estudo de evolução por meio da embriologia comparativa, que, associada às inovações da biologia molecular no final do século XX, definiu o início da produção da evo-devo como disciplina.

Hoje, as linhas de pesquisa enquadradas na evo-devo são inúmeras, mas todas elas se propõem, de maneira geral, a compreender os mecanismos do desenvolvimento que geram variação fenotípica e que têm influência determinante na evolução da forma (Hall, 2003). Questões como "de que forma se originou o desenvolvimento?", "como evoluiu o repertório de desenvolvimento?", "como processos do desenvolvimento estabelecidos são modificados evolutivamente?", "qual a contribuição do desenvolvimento para a geração de variação?", "como são transmitidos mais do que genes no decorrer de gerações?" e "como o meio ambiente interage com o fenótipo?" são algumas das perguntas que envolvem a pesquisa dentro da evo-devo atualmente (Müller, 2008; Laland et al., 2014).

Com o boom da evo-devo no século XXI, surgiu uma polêmica a respeito da possibilidade de uma nova síntese evolutiva que englobasse novos mecanismos evolutivos trazidos pelas pesquisas nessa área. Alguns autores acreditam que as novidades trazidas pela evo-devo não têm aspecto revolucionário e podem ser enquadradas na síntese moderna. Em suma, esses autores assumem a importância que os mecanismos do desenvolvimento apresentam para o processo evolutivo, mas acreditam que o papel do gene é, ainda, central. Advogam que a TSE vem sendo estendida desde sua proposição, especialmente depois da revolução molecular, mas, diante da inegável supremacia do gene, esse processo deve continuar se limitando ao campo prático e experimental (Sandvik, 2000; Richardson, 2003; Laland et al., 2014). Outros defendem que a volta da perspectiva do desenvolvimento no estudo da evolução, respaldada pela biologia molecular, vem demonstrando que os mecanismos evolutivos propostos pela genética de populações não são capazes de explicar o processo evolutivo em larga escala, mas apenas a nível populacional ou de espécies. Acreditam que uma síntese estendida está em emergência, na qual mecanismos como a canalização de traços a partir do desenvolvimento, plasticidade fenotípica, sistemas de herança não genéticos (entre eles a herança epigenética, discutida a seguir, e a herança comportamental), entre outros, serão vistos não mais como 
resultados, mas como causas da evolução (Carroll, 2000; Raff, 2000; Pigliucci, 2007; Carroll, 2008; Laland et al., 2014).

Essa discussão parece estar apenas no começo, mas, apesar disso, o fato é que, indiscutivelmente, o desenvolvimento readquire, em pleno século XXI, grande relevância nos estudos em evolução. Com auxílio da biologia molecular, esses trabalhos confrontaram os evolucionistas com novos dados no campo da genética, principalmente no que diz respeito à evolução da forma, que só podem ser plenamente apreciados se analisados sob a perspectiva do desenvolvimento dos organismos.

Como tantos defenderam durante o século XIX, e aqui se destaca o nome de Darwin, é restabelecido que a evolução não pode ser plenamente compreendida sem o estudo do desenvolvimento. É inevitável, nesse momento, questionar uma ideia quase estabelecida nos estudos teóricos de caráter histórico e/ou filosófico a respeito de Darwin, evolução, herança e genética, ou seja, a ideia de que a teoria da pangênese darwiniana representa apenas um fracasso de Darwin.

Para muitos, o papel da pangênese na história da ciência não pode ir além da desconstrução da imagem do cientista como "gênio", uma vez que sujeito a graves erros de julgamento e interpretação dos fenômenos naturais. Embora esse tipo de análise seja extremamente importante (Allchin, 2003), o papel da pangênese na história da ciência merece ser reavaliado.

Mesmo sem conhecimento dos pares de fatores mendelianos, Darwin elaborou uma teoria coerente para herança inteiramente baseada no pressuposto de que o desenvolvimento era fundamental para a compreensão do processo evolutivo. Muito antes da biologia molecular, Darwin chegou à mesma conclusão a que os teóricos da evo-devo chegam hoje. Assim, a teoria da pangênese representa um exemplo de uma das características do empreendimento científico: é uma atividade humana sujeita ao conhecimento e às técnicas disponíveis em seu tempo e que, portanto, se mostra incapaz de produzir certezas atemporais.

\section{Uma teoria (não)lamarckista}

A teoria da pangênese foi elaborada a partir de uma perspectiva do desenvolvimento e baseada em três pilares: correlação intrínseca dos diferentes tipos de reprodução, a reversão e a herança de caracteres adquiridos (HCA). Dentre esses pilares, a HCA é que tem inspirado a maior parte das leituras históricas modernas sobre a pangênese darwiniana; provavelmente, devido a uma influência da hegemonia da perspectiva genecêntrica da moderna genética. A HCA diz respeito à herança de qualquer modificação no corpo de um indivíduo provocada, necessariamente, por influências externas que tenha ocorrido ao longo da sua vida.

\section{Herança dos caracteres adquiridos}

O conceito de "herança de caracteres adquiridos" é associado hoje, quase que universalmente, ao nome de Jean Baptiste de Lamarck (1744-1829), responsável pela elaboração do primeiro sistema teórico completo em defesa do processo de transmutação das espécies. No entanto, a herança do adquirido era utilizada para explicar a semelhança de descendentes com seus parentais desde a Grécia Antiga (Zirkle, 1946; Martins, 2015), tendo sido Hipócrates de Cós II (460-370 a.C.), considerado o "pai da medicina", um de seus primeiros proponentes (Liu, 2007). 
Mais que isso, tanto no século XVIII, quando Lamarck elaborou sua teoria evolutiva, quanto no século XIX, quando Darwin elaborou sua teoria de herança, a HCA era uma ideia aceita quase como senso comum. Lamarck não fez mais do que incluí-la como pressuposto fundamental de sua teoria, sem propor nenhum mecanismo para tal (Mayr, 1972; Martins, 2015).

As verdadeiras novidades do sistema de Lamarck para explicar a variação das espécies estavam nas duas primeiras leis - "tendência para o aumento da complexidade" e "surgimento de órgãos em função de necessidades que se fazem sentir e se mantém" - que surgiram apenas nas versões finais de sua teoria, publicadas no livro Histoire naturelle des animaux sans vertèbres (1815). Apesar da noção de progressão da cadeia animal no sentido da perfeição ser, também, uma ideia já defendida na comunidade científica, nesse ponto, Lamarck foi mais adiante. Ele propôs um processo materialista e mecanicista pelo qual as espécies sofreriam mudanças ao longo do tempo (em contraposição à visão fixista da natureza, ainda muito popular em sua época). O sentido dessa mudança seria um aumento gradual das faculdades dos indivíduos por força das necessidades fisiológicas que lhes eram impostas pelo meio, formando, assim, uma escala de progressão, a qual é bem detalhada por ele. Essa escala partiria de diferentes linhagens, o que demarcava outra particularidade da teoria de Lamarck em relação às demais que defendiam uma única linha de progressão dos animais na natureza (Lamarck, 1815; Martins, 1997, 2013; Rodrigues, Silva, 2011).

Apesar disso, muitos autores afirmam que a teoria da pangênese de Darwin não passa de uma reapresentação das "leis lamarckistas" do uso e desuso e da herança de caracteres adquiridos (Geison, 1969, p.379). Contudo, uma vez que essas duas leis não eram novidades da teoria de Lamarck - ambas foram, inclusive, associadas à transmutação das espécies por Erasmus Darwin (1731-1802) (Zirkle, 1946, p.115) - e não traziam novas perspectivas em relação ao que já se discutia no meio científico, considera-se a afirmação equivocada. Darwin foi muito além de Lamarck na sua teoria da pangênese e, portanto, de todo o consenso de sua época em relação à herança. Ele ofereceu um mecanismo fisiológico para o fenômeno da HCA e, consequentemente, a possibilidade de seu estudo sistemático. Esse fato não é de se estranhar, uma vez que a teoria de Lamarck era, fundamentalmente, uma teoria sobre a evolução, e a pangênese darwiniana era fundamentalmente uma teoria a respeito de herança e desenvolvimento.

A noção de herança do adquirido começou a perder força apenas no final do século XIX, com a publicação do livro de August Weismann (1834-1914) The germ-plasm theory (1893). Nesse livro o autor enunciou sua famosa "teoria da continuidade do plasma germinativo", na qual propõe a existência de uma separação entre o soma (células que compõe o corpo) e o germe (células reprodutivas), conhecida como barreira de Weismann. Essa teoria foi um marco no século XIX, definindo que apenas a informação presente no plasma germinativo poderia ser herdada. Em pouco tempo a teoria de Weismann seria testada e conquistaria larga aceitação na comunidade científica.

Posteriormente, logo no início do século XX, seria inaugurada a genética moderna, com a redescoberta dos trabalhos de Mendel. A herança genética, somada à separação entre células somáticas e células germinativas, culminou no total descrédito da HCA. Dessa forma, no século XX, o modelo mendeliano de herança e a TSE promovem a superação categórica dos dois grandes eixos da teoria da pangênese darwiniana: a HCA e o desenvolvimento. 
Há menos de cinco décadas, qualquer trabalho que trouxesse alguma discussão a respeito da herança de caracteres adquiridos só poderia reforçar sua incompatibilidade com a genética mendeliana. Contudo, a revolução molecular na biologia que se iniciou ao final de século XX trouxe, em pouco tempo, evidências de que os mecanismos de expressão gênica e herança são muito mais complexos do que se imaginava (Solha, Silva, 2004). E, nesse contexto, percebeuse que fatores externos (ambientais) provavelmente exerciam muito mais influência sobre o desenvolvimento dos seres vivos que o assumido até então.

\section{Pangênese e epigenética}

A renovação da biologia do desenvolvimento (antes sinônimo de embriologia, agora o estudo de todos os aspectos do desenvolvimento tanto numa perspectiva genética quanto epigenética) a partir do final do século XX abriu espaço para o desenvolvimento de diversas linhas de pesquisa que se haviam mantido marginais desde a elaboração da teoria sintética. Duas das disciplinas instituídas nesse processo seriam a evo-devo, como já visto, e, tangenciando-a, a epigenética.

Desde a sua proposição por Waddington (1942), o termo "epigenética" foi utilizado em diferentes sentidos, sendo difícil a obtenção de uma definição geral. Inicialmente, a epigenética se relacionava ao interesse de pesquisadores nas áreas de genética e biologia do desenvolvimento nos fatores responsáveis por promover a diferenciação celular a partir de um único genótipo. As explicações dos padrões de herança observados eram buscadas a nível mitótico, ou seja, como informações epigenéticas eram passadas da célula-mãe para as células-filhas. A associação desses estudos com o termo "epigenética", no entanto, ainda era rara (Holliday, 2005).

A epigenética adquiriu, posteriormente, uma definição mais elaborada e passou a disputar espaço com a genética do desenvolvimento, dentro da grande biologia do desenvolvimento, no sentido de que, como marcaram Jablonka e Lamb (2002), a genética do desenvolvimento estava preocupada com o acoplamento da variação genotípica à variação fenotípica, enquanto a epigenética estava preocupada com desacoplamento da variação genotípica da variação fenotípica, tanto quando a variação no genótipo não produzia nenhuma variação sobre o fenótipo como quando a variação do fenótipo não poderia ser explicada por uma variação no genótipo. Hoje, os estudos voltados para o desenvolvimento envolvendo expressão gênica já pressupõem a existência de redes complexas de interação entre genes e fatores epigenéticos dando origem às variações fenotípicas, superando a contradição ingênua entre as perspectivas genética e epigenética do desenvolvimento.

Com a popularização da biologia do desenvolvimento e sua estirpe evolutiva, a evodevo, começou a surgir uma diversidade de trabalhos voltados para uma perspectiva mais epigenética de produção e análise de dados moleculares. Metilação de DNA, configurações cromossômicas, interferência de RNA e alguns padrões de sinalização celular vêm sendo os principais mecanismos epigenéticos estudados para explicar os fenômenos epigenéticos tais como diferenciação e herança somática, herança meiótica, imprinting etc. (Holliday, 2005).

Um experimento clássico de investigação das metilações de DNA (mecanismo epigenético mais estudado) é o de Randy Jirtle e seu grupo (Watterland, Jirtle, 2003; Dolinoy et al., 2006). Estudando ratos agouti (portadores do gene agouti), eles promoveram a metilação 
(e consequentemente a inibição da expressão) desse gene em novas gerações de ratos produzidas no laboratório. Isso foi feito a partir de uma alimentação rica em radicais metil que era fornecida às mães, antes e durante a gestação. A cor amarelada da pelagem e a tendência para obesidade, características relacionadas ao gene agouti, foram suprimidas da prole. Ou seja, o efeito de um fator ambiental (alimentação das mães) teve efeito direto sobre os ratos da prole sem que houvesse nenhuma mudança em suas sequências de DNA.

O campo de estudo da epigenética, atualmente, encontra-se razoavelmente estabelecido, mas a palavra é, ainda hoje, utilizada em sentidos diversos, bem diferentes daquele cunhado por Waddington. Entre todas as novidades evidenciadas pela epigenética, uma tornou-se particularmente popular e controversa: o fenômeno da herança epigenética (ou herança meiótica, ou, ainda, herança epigenética transgeracional). Sendo os sistemas de herança celular a base de estudo da epigenética, a herança epigenética é, justamente, o fenômeno de herança de marcações epigenéticas, não somente no nível do desenvolvimento (nível celular, mitótico), mas por gerações. Nem toda a variação epigenética é herdada, e, muitas vezes, quando herdada, mantém-se por poucas gerações. Porém, já foram evidenciados casos de herança epigenética estável por dezenas de gerações, o que promove hoje intensa discussão a respeito da influência que esse fenômeno pode ter sobre o processo evolutivo (Jablonka, Lamb, 2010).

Curiosamente, herança epigenética é para muitos, hoje, sinônimo de epigenética, e isso se deve à grande difusão desse em face de sua constante e polêmica associação ao nome de Lamarck (Sano, 2002; Haig, 2007; Burggren, 2014). Jablonka e Lamb (1995) denominaram a herança epigenética como a dimensão lamarckiana da evolução. No entanto, quando se referem à epigenética como neo-lamarckista, não poderiam associá-la às leis da "tendência para o aumento da complexidade" e do "surgimento de órgãos em função de necessidades que se fazem sentir e se mantêm" - as verdadeiras novidades da teoria de Lamarck. Estas leis se contrapõem veementemente ao processo evolutivo como o entendemos hoje (na perspectiva darwiniana), em que não há lugar para a ideia de progresso.

Como visto anteriormente, para Lamarck, as variações novas - mudanças que ocorriam nos indivíduos ao longo de suas vidas - surgiam com função determinada, como uma resposta a uma necessidade do organismo. Seriam, portanto, necessariamente úteis à sobrevivência dos organismos e à manutenção da espécie. Tendo em vista que, de acordo com o conhecimento atual, as variações têm como origem primária mutações genéticas ou epigenéticas, e que, em última instância, essas mutações são cegas, aleatórias, a mudança específica que ocorrerá por meio de uma mutação não pode sequer ser deduzida previamente, muito menos atender a qualquer "necessidade" do organismo. Dessa forma, a teoria evolutiva de Lamarck não só nada tem a ver com a epigenética, como contradiz em mais de um aspecto a concepção de evolução que contorna todos os campos de estudo atuais dentro das ciências biológicas, incluindo, portanto, a epigenética.

De fato, não é a concepção de mudanças evolutivas como respostas a necessidades específicas que representa a associação da epigenética à teoria lamarckista feita pelos teóricos da área. O objetivo da comparação é fazer referência à lei da HCA, pois, uma vez que variações epigenéticas podem surgir por estímulo externo, ambiental, a herança epigenética pressupõe a possibilidade de herança transgeracional estável de mudanças provocadas pelo estilo de vida do indivíduo (mesmo que sem alteração da sequência de DNA). 
A epigenética, portanto, parece ter muito mais em comum com a teoria da pangênese darwiniana que com a teoria de Lamarck. Partindo do fato de que a teoria de Lamarck é, fundamentalmente, uma teoria evolutiva, enquanto a teoria da pangênese é uma teoria de herança, e/ou variação, e/ou desenvolvimento, é possível afirmar que existe mais afinidade da moderna epigenética com a "hipótese provisória da pangênese" de Darwin. Além disso, ao contrário da teoria de Lamarck, a pangênese, uma vez alinhada à teoria evolutiva darwiniana, não pressupõe a noção de melhora.

Ainda permanece, no entanto, o incômodo de que a HCA do século XIX entra em contradição direta com a noção, até hoje bem estabelecida, de continuidade do plasma germinativo. Porém, uma análise mais cuidadosa da teoria da pangênese nesse aspecto revela que a contradição só se aplica a uma visão ingênua da HCA (herança soma-soma), como a reproduzida por Lamarck. Darwin, corroborando a HCA, propôs um mecanismo de desenvolvimento em que as variações adquiridas ao longo da vida fossem incorporadas à linhagem germinativa e, somente desse modo, seriam herdadas ao longo das gerações (Griesemer, 1998). Embora o mecanismo em si seja falho (o que, de novo, não surpreende, considerando as ferramentas de estudo disponíveis na época), a proposta é, em muitos níveis, afinada ao que se entende hoje por herança epigenética.

Embora Lamarck tenha exercido papel importante em sua época com sua teoria evolutiva, rejeitando o fixismo e abrindo mão de causas sobrenaturais para explicar a biodiversidade, sua fama ficou restrita àquilo com que ele menos se preocupou - a herança. Quando comparadas às qualidades da herança por Lamarck e da herança por Darwin, a associação entre epigenética e Lamarckismo parece um mero artifício de marketing ante a maior afinidade que existe entre esta e a teoria da pangênese. Nas palavras de Griesemer (1998, p.106) em sua revisão de Jablonka e Lamb (1995): "Eu apenas gostaria que elas houvessem alegado em seu subtítulo que a herança epigenética é a 'dimensão pangenética', ao invés da dimensão lamarckiana”. ${ }^{13}$ Aqui, mais uma vez, o rótulo de fracasso da teoria darwiniana de herança parece não lhe fazer jus.

\section{Considerações finais}

O objetivo explícito deste trabalho foi elaborar a defesa de um argumento particular: a pangênese darwiniana não deveria ser relegada, na história da ciência, ao lugar de teoria equivocada e anacrônica. Para isso, buscou-se contextualizar brevemente o ambiente científico em que Darwin desenvolveu sua hipótese provisória e os motivos que o teriam levado a escrevê-la e publicá-la. Afinal, "compreender a instrução do momento é tão importante quanto expor as razões da destruição na sequência" (Canguilhem, 2012, p.7). Nesse sentido, a teoria darwiniana demonstra absoluta coerência com seu tempo, fato que à primeira vista já invalida qualquer discurso de desvalorização das ideias de herança de Darwin. Em tempo, a despeito do fato dos resultados de Darwin com cruzamento de variedades de boca-de-leão (Antirrhinum majus) terem apresentado valores equivalentes às razões mendelianas de herança (Jablonka, Lamb, 2010, p.174), e ele ter tido contato com o trabalho de Mendel (Bizzo, 1999), ele não foi capaz de usar o modelo mendeliano de herança em favor da sua teoria. Isso se deu, provavelmente, pelo fato de que Darwin estava em um ambiente científico francamente favorável à ideia de "herança dos caracteres adquiridos". Como bem pontuou Bizzo (2012, 
p.131) em relação a esse fato, "ao observar a natureza, e mesmo ao ler um livro, é impossível que o cientista deixe de projetar suas convicções e interesses".

No intuito de discutir a relevância histórica da teoria da pangênese, utilizou-se, além da sua contextualização ao ambiente científico da época, uma análise do que se assume hoje, no século XXI, por desenvolvimento e herança (dois temas centrais da teoria da pangênese), tendo como foco a evo-devo e a epigenética. Não se pretendeu, contudo, colocar a pangênese numa posição de precursor da evo-devo ou da epigenética. A busca por precursores incorre no risco de cometer erros de anacronismos na interpretação da história de uma ideia ou de um conceito (Martins, 2005). Fatores históricos críticos, como o advento da biologia molecular, separam a pangênese da evo-devo e da epigenética. Menos na história da ciência e mais na epistemologia, a intenção foi explicitar o paralelismo que se apresenta entre a teoria da pangênese, foco do trabalho, e os lugares do desenvolvimento e da herança dos caracteres adquiridos dentro da biologia hoje (especialmente pelo fato de que estes dois foram fatores cruciais para o fracasso da teoria darwiniana em sua época). Dessa forma, o trabalho recai, por fim, sobre a questão da natureza e lógica da ciência.

Numa análise histórica superficial do desenvolvimento das ideias de herança, a teoria da pangênese é facilmente caracterizada apenas como "o fracasso de Darwin". No entanto, quando nos deparamos com o rápido declínio de noções estabelecidas durante séculos (como a herança de caracteres adquiridos, ou a perspectiva da evolução pelo desenvolvimento) e, em seguida, o seu retorno em perspectivas novas do ponto de vista teórico e metodológico, percebe-se que a dinâmica do conhecimento não obedece a uma função linear ou exponencial de crescimento. Assim, não é prudente estabelecer que aquilo que foi jamais virá a ser novamente. A única regra é a da mudança, da transformação; aquilo que vem a ser de novo, o faz por meio da superação do antigo contexto e o estabelecimento de um novo.

Por conseguinte, este texto não defende que se volte a utilizar a pangênese para explicar a herança ou, ainda, que se volte a procurar gêmulas nos fluidos corporais de organismos multicelulares. Desde o início da genética moderna, novos conhecimentos surgiram, e as técnicas e a linguagem dos estudos em herança e evolução sofreram mudanças dramáticas. Portanto, o resgate ingênuo de velhas ideias não faz sentido. Porém, reconstruindo histórica e cientificamente o desenvolvimento das ideias de herança (mesmo que apenas parcialmente), percebe-se que hipóteses e teorias antes ignoradas podem ser ressignificadas à luz dos conhecimentos atuais. Percebe-se que teorias como a pangênese darwiniana, uma vez adequadas ao seu tempo, não podem nem devem ser menosprezadas por sua incongruência com conhecimentos subsequentes, principalmente quando muito do seu foco ressurge nas mais recentes produções da área.

Como frisou Ghiselin (1975, p.55), a teoria da pangênese de Darwin apresentava apenas um grande problema: respondia uma questão do século XVIII - qual a explicação para a semelhança entre descendentes e parentais, atavismo, aberrações? - com o conhecimento do século XIX - evidências empíricas provindas da literatura e do questionário com criadores de gado -, quando a resposta estava no século XX - com a biologia molecular. 


\section{NOTAS}

${ }^{1}$ No original: "The power of Selection... absolutely depends on the variability of organic beings. Without variability nothing can be effected." Nesta e nas demais citações de textos publicados em outros idiomas, a tradução é livre.

${ }^{2}$ Hipótese (do grego hypo, debaixo, e thesis, tese) se define aqui com uma proposição simples de natureza criativa, desenvolvida em bases empíricas e/ou especulativas. Assim, as hipóteses são norteadoras da produção de dados observacionais e/ou experimentais. Assemelham-se às "conjecturas" popperianas (Popper, 1982) ou às "teorias acessórias" de Lakatos (1972). Teoria (do grego theoria, contemplar, examinar, observar) aqui é tomada como um sistema explicativo. Ou seja, envolve uma ou mais hipóteses, um conjunto de observações coerentes com o enredo explicativo e com dados experimentais. Neste sentido é que a pangênese darwiniana é entendida aqui como uma teoria, uma vez que reunia explicações para os fenômenos observados, mais de uma hipótese a respeito da herança (existência das gêmulas, influência do ambiente sobre elas, fenômeno da dormência etc.), evidências empíricas e uma heurística positiva (Galton, 1870, e seus experimentos de transfusão de sangue em coelhos; Darwin, 1871, e sua resposta aos resultados de Galton). Como sistema, a teoria envolve um conjunto de elementos articulados e determina uma série de procedimentos enquanto opera uma explicação. Pode ser dito que, da forma como se define aqui, uma teoria guarda grande semelhança com as noções de fenomenotécnica (Bachelard, 1983), objetos de conhecimento (Althusser, 1985) e concretos de pensamento (Marx, 1858). É importante ressaltar, no entanto, que as referências foram usadas como analogias para as definições que estão sendo utilizadas neste texto, uma vez que autores como Marx/Althusser e Popper/Lakatos, por exemplo, não guardam grandes afinidades de pensamento.

${ }^{3}$ No original: "I assume that cells, before their conversion into completely passive or 'formed material', throw off minute granules or atoms, which circulate freely throughout the system, and when supplied with proper nutriment multiply by self-division, subsequently becoming developed into cells like those from which they were derived. These granules for the sake of distinctness may be called cell gemmules, or, as the cell theory is not fully established, simply gemmules. They are supposed to be transmitted from the parents to the offspring, and are generally developed into the generation which immediately succeeds, but are often transmitted in a dormant state during many generations and are then developed. Their development is supposed to depend on their union with other partially developed cells or gemmules which precede them in the regular course of growth... Gemmules are supposed to be thrown off by every cell or unit, not only during the adult state, but during all the stages of development. Lastly, I assume that the gemmules in their dormant state have a mutual affinity for each other, leading to their aggregation either into buds or into the sexual elements. Hence, speaking strictly, it is not the reproductive system, nor the buds, which generate new organisms, but the cells themselves throughout the body. These assumptions constitute the provisional hypothesis which I have called Pangenesis."

${ }^{4}$ No original: "The most wonderful of all the attributes of Inheritance."

${ }^{5}$ No original: "Finally, we see on the hypothesis of pangenesis variability depends on at least two distinct groups of causes. Firstly, the deficiency, superabundance and transposition of gemmules, and the redevelopment of those which have long been dormant: the gemmules themselves not having undergone any modification; and such changes will amply account for much fluctuating variability. Secondly, the direct action of changed conditions on the organization, and of the increased use or disuse of parts; and in this case the gemmules from the modified units will be themselves modified, and, when sufficiently multiplied, will supplant the old gemmules and be developed into new structures."

${ }^{6}$ No original: "If the right variations occurred and no others natural selection would be superfluous."

${ }^{7}$ No original: "Natural selection has been the main, but not exclusive, means of modification."

${ }^{8}$ No original: "It was an attempt to deal with this developmental aspect of biology, with its evolutionary implications, that was the basic rationale of pangenesis."

${ }^{9}$ Um paradigma é uma teoria geral pela qual, em detrimento de outras, vemos e interpretamos os dados da realidade (uma forma de "viseira conceitual"), ou seja, diferentes paradigmas trazem consigo uma linguagem com a qual descrevemos os dados e uma forma por meio da qual fazemos nossas observações e organizamos nossos experimentos. O termo foi definido assim por Thomas Samuel Kuhn (1922-1996), um físico estadunidense conhecido pelo seu trabalho com a história e a filosofia da ciência. Seu livro mais conhecido é A estrutura das revoluções científicas, publicado em 1962 (Kuhn, 1987).

${ }^{10}$ A redescoberta dos trabalhos de Mendel tem sido questão de debate, especialmente com relação aos trabalhos de Tschermak e De Vries. No caso de Correns, embora a redescoberta não seja discutida, a compreensão dos trabalhos de Mendel por ele é posta em questão (Fisher, 1966; Sturtevant, 1967).

${ }_{11}$ Muitos outros importantes evolucionistas, como Ernst Mayr (1904-2005), Theodosius Dobzhansky (1900-1975), George Gaylord Simpson (1902-1984) e Julian Huxley (1887-1975) (Huxley, 1942; Simpson, 1953; Dobzhansky, 1970; Mayr, 1977), são comumente relacionados à geração da síntese moderna (Mayr, 
1993; Gould, 1994). No entanto, compreende-se que estes três autores (Fisher, Wright e Haldane) foram os responsáveis por solucionar teórica e matematicamente as duas principais questões que limitavam a síntese da teoria evolutiva darwiniana com a herança mendeliana. A primeira questão dizia respeito ao problema de compatibilizar uma teoria de herança atomística (baseada na variação discreta) com a variação contínua claramente presente nas populações naturais. Esse problema foi resolvido por Fisher (1 out. 1918), propondo, basicamente, que um caráter representativo de variação contínua deveria estar se manifestando a partir da interação aditiva de dois ou mais fatores hereditários, ou seja, de diferentes alelos em um ou mais loci. A segunda questão dizia respeito à necessidade de uma demonstração matemática da ação de seleção natural sobre populações mendelianas produzir os efeitos esperados pela teoria darwiniana. Essa demonstração se deu, de maneira independente, nos trabalhos de Fisher (1930), Wright (1931) e Haldane (1932), definindo, resumidamente, que a evolução se daria a partir da mudança das frequências gênicas dentro das populações naturais (Provine, 1971; Lewontin, 1974; Crow, 1987).

${ }^{12}$ A microevolução pode ser entendida como o conjunto de processos evolutivos observáveis em nível de espécie. Diz respeito, portanto, às mudanças de frequências gênicas numa população. Já a macroevolução diz respeito à mudança evolutiva em grande escala, responsável por explicar a origem dos táxons. Eventos macroevolutivos ocorrem na faixa dos milhões de anos e são, geralmente, estudados por meio do registro fóssil.

${ }^{13}$ No original: "I only wish they had claimed in their subtitle that epigenetic inheritance is 'the pangenetic dimension' rather than the Lamarckian dimension."

\section{REFERÊNCIAS}

ALLCHIN, Douglas.

Scientific myth-conceptions. Science Education, v.87, n.3, p.329-351. 2003.

ALTHUSSER, Louis.

Freud e Lacan, Marx e Freud. Rio de Janeiro: Graal. 1985.

ARTHUR, Wallace.

The emerging conceptual framework of evolutionary developmental biology. Nature, v.415, p.757-764. 2002.

BACHELARD, Gaston.

Epistemologia. Rio de Janeiro: Zahar. 1983.

BIZZO, Nelio.

Uma nova história natural: Charles Darwin e as dinâmicas da natureza. In: Bizzo, Nelio. Pensamento científico: a natureza da ciência no ensino fundamental. São Paulo: Melhoramentos. p.86-148. 2012.

BIZZO, Nelio.

A teoria genética de Charles Darwin e sua oposição ao mendelismo. Filosofia e História da Biologia, v.3, p.317-333. 2008.

BIZZO, Nelio.

On the different interpretations of the historical and logical development of the scientific understanding of evolution. In: History and Philosophy of Science and Science Teaching (HPSST) Conference, 4., 1999, Calgary. Proceedings...: HPSST. p.99-112. 1999.

BOWLER, Peter J.

Evolution: history. Encyclopedia of life sciences. Disponível em: http://onlinelibrary.wiley.com/ doi/10.1002/9780470015902.a0001517.pub2/

full. Acesso em: 4 ago. 2017. 2002.

BURGGREN, Warren W.

Epigenetics as a source of variation in comparative animal physiology - or - Lamarck is lookin' pretty good these days. Journal of Experimental Biology, v.217, n.5, p.682-689. 2014.

CANGUILHEM, Georges.

O objeto da história das ciências. In:

Canguilhem, Georges. Estudos de história

e de filosofia das ciências: concernentes aos vivos e à vida. p.1-16. Rio de Janeiro: Forense Universitária. 2012.

CARROLL, Robert Lynn.

Towards a new evolutionary synthesis. Tree, v.15, n.1, p.27-32. 2000.

CARROLL, Sean B.

Evo-devo and an expanding evolutionary synthesis: a genetic theory of morphological evolution. Cell, v.134, n.1, p.25-36. 2008.

CROW, James F.

Population genetics history: a personal view. Annual Review of Genetics, v.21, p.1-22. 1987.

DARWIN, Charles Robert.

The variation of animals and plants under

domestication. London: John Murray. 1875.

DARWIN, Charles Robert.

Pangenesis. Nature, v.3, n.78, p.502-503. 1871.

DARWIN, Charles Robert.

Darwin, C.R. to Gray, A. Darwin Correspondence 
Database. Disponível em: http://www. darwinproject.ac.uk/entry-6167. Acesso em: 14 abr. 2015. 8 maio 1868 .

DARWIN, Charles Robert.

The variation of animals and plants under domestication. London: John Murray. 1868.

DARWIN, Charles Robert.

Darwin, C.R. to Lyell, C. Darwin Correspondence Database. Disponível em: http://www.

darwinproject.ac.uk/entry-5612. Acesso em: 14 abr. 2015. 22 ago. 1867.

DARWIN, Charles Robert.

Darwin, C.R. to Huxley, T.H. Darwin

Correspondence Database. Disponível em: http:// www.darwinproject.ac.uk/entry-4872. Acesso em: 13 jul. 2015. 17 jul. 1865.

DARWIN, Charles Robert.

On the origin of species. London: John Murray. 1859.

DOBZHANSKY, Theodozius.

Genetics of the evolutionary process. London: Columbia University Press. 1970.

DOBZHANSKY, Theodosius.

Genetics and the origin of species. New York: Columbia University Press. 1937.

DOLINOY, Dana C. et al.

Maternal genistein alters coat color and protects $\mathrm{A}^{\mathrm{vy}}$ mouse offspring from obesity by modifying the fetal epigenome. Environmental Health Perspectives, v.114, n.4, p.567-572. 2006.

DUBOULE, Denis; DOLLÉ, Pascal.

The structural and functional organization of the murine HOX gene family resembles that of Drosophila homeotic genes. Embo, v.8, n.5, p.1497-1505. 1989.

FISHER, Ronald Aylmer.

Has Mendel's work been rediscovered? In: Stern, Curt; Sherwood, Eva R. (Ed.). The origin of genetics: a Mendel source book. San Francisco: W.H. Freeman. p.139-172. 1966.

FISHER, Ronald Aylmer.

The genetical theory of natural selection. Oxford: Oxford University Press. 1930.

FISHER, Ronald Aylmer.

The correlation between relatives on the supposition of Mendelian inheritance. Transactions of the Royal Society of Edinburgh, v.52, p.399-433. 1 out. 1918.

GALTON, Francis.

Experiments in pangenesis. Proceedings of Royal Society of London, v.19, p.393-410. 1870.

GEISON, Gerald L.

Darwin and heredity: the evolution of his hypothesis of pangenesis. Journal of the History of Medicine and Allied Sciences, v.24, n.4, p.375-411. 1969.

GHISELIN, Michael T.

The rationale of pangenesis. Genetics, v.79, p.4757. 1975.

GILBERT, Scott F.; OPITZ, John M.; RAFF,

Rudolf A.

Resynthesizing evolutionary and developmental biology. Developmental Biology, v.173, n.2, p.357372. 1996.

GOULD, Stephen Jay.

Ernest Mayr and the centrality of species.

Evolution, v.48, n.1, p.31-35. 1994.

GOULD, Stephen Jay.

Ontogeny and phylogeny. Cambridge: The Belknap Press of Harvard University Press. 1977.

GRAHAM, Anthony; PAPALOPULU, Nancy; KRUMLAUF, Robb.

The murine and Drosophila homeobox gene complexes have common features of organization and expression. Cell, v.57, n.3, p.367-378. 1989.

GRIESEMER, James.

Turning back to go forward: a review of 'Epigenetic inheritance and evolution: the Lamarckian dimension', by Eva Jablonka and Marion Lamb. Biology and Philosophy, v.13, n.1, p.103-112. 1998.

HAECKEL, Ernst.

Generelle Morphologie der Organismen. Berlin: Georg Reimer. 1866.

HAIG, David.

Weismann rules! OK? Epigenetics and the Lamarckian temptation. Biology and Philosophy, v.22, n.3, p.415-428. 2007.

HALDANE, John B.S.

The causes of evolution. London: Longsman, Green. 1932.

HALL, Brian K.

Evo-devo: evolutionary development mechanisms. International Journal of Biological Sciences, v.47, n.7-8, p.491-495. 2003.

HOLLIDAY, Robin.

Epigenetics: a historical overview. Epigenetics, v.1, n.2, p.76-80. 2006.

HOLLIDAY, Robin.

DNA methylation and epigenotypes.

Biochemistry, v.70, n.5, p.500-504. 2005.

HUXLEY, Julian.

Evolution, the modern synthesis. New York: Harper Brothers. 1942. 
HUXLEY, Thomas Henry.

Huxley, T.H. to Darwin, C.R. Darwin

Correspondence Database. Disponível em: http:// www.darwinproject.ac.uk/entry-4875. Acesso em: 13 jul. 2015. 16 jul. 1865.

JABLONKA, Eva; LAMB, Marion J.

Evolução em quatro dimensões: DNA,

comportamento e a história da vida. São Paulo:

Companhia das Letras. 2010.

JABLONKA, Eva; LAMB, Marion J.

The changing concept of epigenetics. Annals of the New York Academy of Sciences, v.981, p.82-96. 2002.

JABLONKA, Eva; LAMB, Marion J.

Epigenetic inheritance and evolution: the

Lamarckian dimension. Oxford: Oxford

University Press. 1995.

JENKIN, Henry Charles Fleeming.

The origin of species. North British Review, v.46, n.92, p.277-318. 1867.

KUHN, Thomas Samuel.

A estrutura das revoluções científicas. São Paulo:

Perspectiva. 1987.

LAKATOS, Imre.

Falsification and the methodology of scientific research programmes. In: Lakatos, Imre;

Musgrave, Alan (Ed.). Criticism and the growth of knowledge. Cambridge, UK: Cambridge University Press. p.91-196. 1972.

LALAND, Kevin et al.

Does evolutionary theory need a rethink? Nature, v.514, n.7521, p.161-164. 2014.

LAMARCK, Jean Baptiste Pierre Antoine de Monet, chevalier de.

Histoire naturelle des animaux sans vertebres. Paris: Verdière. 1815.

LEWONTIN, Richard C.

The genetic basis of evolutionary change. New York: Columbia University Press. 1974.

LIU, Yongsheng S.

Like father like son: a fresh review of the inheritance of acquired characteristics. European Molecular Biology Organization, v.8, n.9, p.798803. 2007.

LIU, Yongsheng S.; LI, Xiuju J.

Does Darwin's pangenesis have fatal flaws?

International Journal of Epidemiology, v.41, n.5, p.1492-1493. 2012.

MARTINS, Lilian Al-Chueyr Pereira.

A herança de caracteres adquiridos nas teorias "evolutivas" do século XIX, duas possibilidades: Lamarck e Darwin. Filosofia e História da Biologia, v.10, n.1, p.67-84. 2015.
MARTINS, Lilian Al-Chueyr Pereira.

Lamarck e a progressão da escala animal. Filosofia e História da Biologia, v.8, n.3, p.569-586. 2013.

MARTINS, Lilian Al-Chueyr Pereira.

História da ciência: objetos, métodos e

problemas. Ciência e Educação, v.11, n.2, p.305-

317. 2005.

MARTINS, Lilian Al-Chueyr Pereira.

Lamarck e as quatro leis da variação das espécies. Epistéme, v.2, n.3, p.33-54. 1997.

MARX, Karl.

Grundrisse. London: Pelican. 1858.

MAYR, Ernst.

What was the evolutionary syntesis? Trends in

Ecology and Evolution, v.8, n.1, p.31-34. 1993.

MAYR, Ernst.

Populações, espécies e evolução. São Paulo:

Companhia Editora Nacional; Editora da Universidade de São Paulo. 1977.

MAYR, Ernst.

Lamarck revisited. Journal of the History of Biology, v.5, n.1, p.55-94. 1972.

MCGINNIS, William et al.

A homologous protein-coding sequence in Drosophila homeotic genes and its conservation in other metazoans. Cell, v.37, n.2, p.403-408. 1984.

MENDEL, Gregor.

Experiments on plant hybrids. In: Stern, Curt; Sherwood, Eva R. (Ed.). The origins of genetics: a Mendel source book. San Francisco: W.H. Freeman. p.1-48. 1865.

MÜLLER, Gerd B.

Evo-devo as a discipline. In: Mineli, Alessandro; Fusco, Guiseppe (Ed.). Evolving pathways: key themes in evolutionary developmental biology. Cambridge: Cambridge University Press. p.3-29. 2008.

OLBY, Robert C.

Origins of mendelism. London: Constable. 1966.

OLBY, Robert C.

Charles Darwin's manuscript of pangenesis.

British Journal for the History of Science, v.1, n.3, p.251-263. 1963.

PICK, Leslie; HEFFER, Alison.

Hox gene evolution: multiple mechanisms contributing to evolutionary novelties. Annals of the New York Academy of Sciences, v.1256, p.15-32. 2012.

PIGLIUCCI, Massimo.

Do we need an extended evolutionary synthesis? Evolution, v.61, n.12, p.2743-2749. 2007. 
POPPER, Karl.

Conjecturas e refutações. Brasília: Editora da Universidade de Brasília. 1982.

PROVINE, William B.

The origins of theoretical population genetics.

Chicago: The University of Chicago Press. 1971.

RAFF, Rudolf A.

Evo-devo: the evolution of a new discipline.

Nature Reviews Genetics, v.1, n.1, p.74-79. 2000.

RICHARDSON, Michael K.

A naturalist's evo-devo. Nature Genetics, v.34, n.4, p.351. 2003.

RODRIGUES, Rodolfo F.C.; SILVA, Edson Pereira. Lamarck: fatos e boatos. Ciência Hoje, v.48, n.285, p.68-70. 2011.

SANDVIK, Hano.

A new evolutionary synthesis: do we need one? Trends in Ecology and Evolution, v.15, n.5, p.205. 2000.

SANO, Hiroshi.

DNA methylation and Lamarckian inheritance. Proceedings of the Japan Academy, Serie B, v.78, n.10, p.293-298. 2002.

SCOTT, Matthew P.; WEINER, Amy J.

Structural relationships among genes that control development: sequence homology between the Antennapedia, Ultrabithorax, and fushi tarazu loci of Drosophila. Proceedings of the National Academy of Sciences of the United States of America, v.81, n.13, p.4115-4119. 1984.

SILVA, Edson Pereira.

A short history of evolutionary theory. História, Ciências, Saúde - Manguinhos, v.8, n.3, p.671-687. 2001.

SILVA, Edson Pereira; ANDRADE, Luiz Antônio Botelho de.

Para um estudante de biologia saber. Niterói:

Coordenação de Educação a Distância/

Universidade Federal Fluminense. 2012.
SIMPSON, George G.

The major features of evolution. New York:

Columbia University Press. 1953.

SOLHA, Gustavo C.F.; SILVA, Edson Pereira.

Onde está o lugar do conceito de gene? Episteme, v.19, p.45-68. 2004.

STURTEVANT, Alfred Henry.

A history of genetics. New York: Cold Spring Harbor Laboratory Press/Electronic Scholarly Publishing Project. 1967.

VORZIMMER, Peter.

Charles Darwin and blending inheritance. Isis, v.54, n.3, p.371-390. 1963.

WADDINGTON, Conrad H.

The epigenotype. Endeavour, v.1, p.18-20. 1942.

WATTERLAND, Robert A.; JIRTLE, Randy L.

Transposable elements: targets for early

nutritional effects on epigenetic gene regulation. Molecular and Cellular Biology, v.23, n.15, p.52935300. 2003.

WEISMANN, August.

The germ-plasm theory: a theory of heredity. New York: Charles Scribner's Sons. 1893.

WINTHER, Rasmus G.

Darwin on variation and heredity. Journal of the History of Biology, v.33, n.3, p.425-455. 2000.

WRIGHT, Sewall.

Evolution in mendelian populations. Genetics, v.16, n.2, p.97-159. 1931.

ZIRKLE, Conway.

The early history of the idea of the inheritance of acquired characters and of pangenesis.

Transactions of the American Philosophical Society, v.35, n.2, p.91-151. 1946. 